\title{
Experimental off-pump transventricular pulmonary valve replacement using a self-expandable valved stent: A new approach for pulmonary incompetence after repaired tetralogy of Fallot?
}

\author{
François Godart, MD, PhD, ${ }^{\mathrm{a}, \mathrm{d}}$ Ivan Bouzguenda, MD, ${ }^{\mathrm{a}, \mathrm{d}}$ Francis Juthier, MD, ${ }^{\mathrm{b}, \mathrm{d}}$ Fabrice Wautot, MD, ${ }^{\mathrm{b}, \mathrm{d}}$ Alain Prat, MD, ${ }^{\mathrm{b}, \mathrm{d}}$ \\ Christian Rey, MD, ${ }^{\text {a }}$ Delphine Corseaux, PhD, ${ }^{\mathrm{c}, \mathrm{d}}$ Alexandre Ung, ${ }^{\mathrm{d}}$ Brigitte Jude, MD, PhD, ${ }^{\mathrm{c}, \mathrm{d}}$ and André Vincentelli, MD, PhD ${ }^{\mathrm{b}, \mathrm{d}}$
}

Objective: Off-pump valve replacement using self-expandable stents is an emerging technique for pulmonary valve disease. However, significant limitations are the lack of easily available valve substitute to be inserted within the stent and, in the setting of repaired tetralogy of Fallot, the existence of huge pulmonary trunk. We report the first experimental results of a transventricular approach using a decellularized porcine xenograft mounted in a self-expandable stent.

Methods: Pulmonary valve replacement was realized in 15 lambs by direct access of the infundibulum through a left thoracotomy, combined with pulmonary artery banding. Animals were followed by transthoracic echocardiography and, after control hemodynamic study, were electively killed either at day 7, month 1, or month 4 after implantation.

Results: Implantation succeeded in all lambs. Two animals died after implantation (1 pneumothorax and 1 endocarditis). Doppler echocardiographic follow-up did not show any significant transvalvular gradient and showed only mild pulmonary regurgitation. The hemodynamic control before termination revealed a systolic pulmonary valve gradient of $18.5 \pm 12.4 \mathrm{~mm} \mathrm{Hg}$ at 1 week $(\mathrm{n}=4), 13.5 \pm 10.6 \mathrm{~mm} \mathrm{Hg}$ at 1 month $(\mathrm{n}=4)$, and $4.3 \pm 4.9$ $\mathrm{mm} \mathrm{Hg}$ at 4 months $(\mathrm{n}=5)$. Gross examination demonstrated the presence of connective tissue between the valved stent and pulmonary wall, which increased with time.

Conclusion: Fifteen lambs underwent successful deployment of a self-expandable valved stent in the pulmonary position using a transventricular approach. This technique combined with pulmonary artery banding could be a therapeutic option for pulmonary insufficiency after repair of tetralogy of Fallot with a transannular patch.

In patients with congenital heart disease who had surgical pulmonary valvectomy or transannular pulmonary patch, the pulmonary regurgitation can lead to severe right ventricular failure. The classical surgical repair under cardiopulmonary bypass remains the first-line treatment to replace the pulmonary valve but may in fact deteriorate the right ventricular function. ${ }^{1}$ More recently, different alternatives have been proposed such as percutaneous implantation or transventricular approach. ${ }^{2-6}$ This latter is obviously more invasive for the patient than the transvenous insertion but

\footnotetext{
From the Pôle de Cardiologie et Maladies Vasculaires, Centre Hospitalier Régional et Universitaire de Lille, Service des Maladies Cardiovasculaires Infantiles et Congénitales, ${ }^{a}$ Pôle de Chirurgie Cardiovasculaire, ${ }^{b}$ Pôle d'Hémato-Transfusion, ${ }^{\mathrm{c}}$ Lille cedex, France; and Université de Lille 2, EA 2693, ${ }^{\mathrm{d}}$ Faculté de Médecine de Lille, Lille cedex, France.

This work was realized in Institut Fédératif de Recherche 114 and was supported by grants from University of Lille 2 (EA2693), from the French Fond National pour la Science, Ministère de la Recherche (Action Concertée Incitative 2002-Grant 02TS 050), from Conseil Régional Nord Pas de Calais (2003-OBJ2-2004/1-4-1, No. 157) and "ESPRI",/FEDER R04026EE, and from the French Society of Cardiology (Hélène de Marsan) and Sesserac.

Received for publication March 30, 2008; revisions received June 9, 2008; accepted for publication July 5, 2008

Address for reprints: François Godart, MD, PhD, Pôle de Cardiologie et Maladies Vasculaires, Service des Maladies Cardiovasculaires Infantiles et Congénitales, Hôpital Cardiologique, CHRU de Lille, 59037 Lille cedex, France (E-mail: f-godart@ chru-lille.fr)

J Thorac Cardiovasc Surg 2009;137:1141-5

0022-5223/\$36.00

Copyright (c) 2009 by The American Association for Thoracic Surgery

doi:10.1016/j.jtcvs.2008.07.057
}

allows a pulmonary valve replacement without the need of a cardiopulmonary bypass and is not limited to reduced valve diameter by small catheters or vessel dimensions. Using such an approach, the first implantations in humans were reported by Berdat and $\mathrm{Carrel}^{5}$ with a porcine pulmonic valve mounted on a self-expandable stent, and then later by a German team. ${ }^{6}$ The reported results were very promising, but both groups experienced significant drawbacks such as paravalvular leakage and valve migration requiring further surgery. We report here our results of an experimental study of an off-pump pulmonary valve implantation without cardiopulmonary bypass, through a transventricular approach using a decellularized porcine xenograft mounted in a self-expandable stent, and combined with pulmonary artery reduction.

\section{MATERIAL AND METHODS}

All animals received humane care in accordance with the "Principles of Laboratory Animal Care" and the "Guide for the Care and Use of Laboratory Animals" (National Institutes of Health publication No. 85-23, revised 1985).

\section{Preparation of the Valve}

The selected valve was a decellularized porcine xenograft, prepared in our laboratory as previously described from female piglets (Large White/ Landras, $20-25 \mathrm{~kg}$ body weight). ${ }^{7}$ The procedure was performed after median sternotomy under surgical conditions. Porcine pulmonic root tissue was obtained from fresh dissection and a blade-cleaning procedure to remove excess connective tissue and myocardium, leaving a thin ridge of 


\section{Abbreviation and Acronym \\ $\mathrm{RVOT}=$ right ventricular outflow tract}

subvalvular muscle tissue proximally and a short arterial segment distally (Figure 1, A). The porcine valve conduits were then calibrated with a Hegar dilator. The classical preparation using glutaraldehyde was replaced here by techniques of hypotonic nonenzymatic solutions..$^{7-9}$ This decellularized xenograft has been demonstrated to sustain physiologic shear stress. ${ }^{7}$

\section{Preparation of the Valved Stent and Delivery System}

A self-expandable stent made of nitinol, which is a memory-shape alloy (Bard Luminexx; Angiomed GmbH, Karlsruhe, Germany), was employed (30 $\mathrm{mm}$ in length and $18 \mathrm{~mm}$ in diameter). On the same day of implantation, the porcine valve described above was sewed distally and proximally by running suture in the stent (Figure 1, $B$ ). To avoid hammock aspect of the valve, additional sutures were realized in the middle part of the valved stent on 4 cardinal points, and the valve was immersed in saline solution until the implantation (Figure 1,C). The delivery system consisted of a front-loading 22/24-French sheath with outer diameter constant on all its length (Gore Introducer Sheath, Gore and Associates, Flagstaff, Ariz). The inner dilator was distally modified to receive the valved stent within the sheath. It had also a 2$\mathrm{cm}$ conical-shaped tip to allow smooth transition between the tip and the sheath, thus limiting the risk of trauma of ventricle or vessel wall at implantation. The valved stent was loaded by hand-crimping into the previously described delivery system just before release to minimize time of valve compression within the sheath.

\section{Technique of Valve Placement}

Valved stents were implanted in lambs (Romanov/Ile de France, 22-34 $\mathrm{kg}$ body weight). Animals were placed in right lateral position. In each case, a catheter was placed in the jugular vein to gain access for delivery of medication and a second one in a small artery on the ear to monitor the blood pressure. General anesthesia was induced by means of intravenous injection of propofol (500 $\left.\mu \mathrm{g} \mathrm{kg}^{-1} \mathrm{~min}^{-1}\right)$ and sufentanil $(0.5 \mu \mathrm{g} / \mathrm{kg}$ body weight $)$ followed by a continuous venous injection of propofol $\left(500 \mu \mathrm{g} \mathrm{kg}^{-1}\right.$ $\left.\mathrm{min}^{-1}\right)$ and sufentanil $\left(1 \mu \mathrm{g} \mathrm{kg}^{-1} \mathrm{~h}^{-1}\right)$. Lambs were intubated and mechanically ventilated. Cardiac and respiratory functions were monitored during the entire procedure. Systemic anticoagulation was induced with heparin
(300 UI/ $\mathrm{kg})$. All animals received xylocaine $(1 \mathrm{mg} / \mathrm{kg}$ ) to prevent ventricular arrhythmia and were perfused with isotonic saline solution.

A thoracotomy was performed through the fourth left intercostal space. The main pulmonary artery was first dissected free to allow placement of a band around the trunk. The band was tightened to reduce the diameter just below $18 \mathrm{~mm}$ and avoid distal embolization of the valved stent in pulmonary vasculature. Then to correctly visualize the pulmonary annulus at implantation, 2 radiopaque markers were placed on the pulmonary artery trunk: the first at the level of the annulus and the second at the distal band. The site of puncture on the right ventricular outflow tract (RVOT) was secured by a purse using a 3-0 polypropylene filament and 2 Teflon felts separated by $15 \mathrm{~mm}$. The right ventricular infundibulum was punctured about $2 \mathrm{~cm}$ beneath the pulmonary annulus in the direction of the pulmonary trunk by a 16-gauge needle. A 0.035 -inch guide wire was advanced in the lumen of needle and the left pulmonary artery, and the needle was replaced by a 6-French Radifocus Introducer II (Terumo Corporation, Tokyo, Japan). Under fluoroscopic guidance, the initial guide wire was exchanged for a 260-cm-long 0.035-inch Rosen curved guide wire (Cook; William Cook Europe, Bjaeverskov, Denmark) placed in the distal left pulmonary artery. The large introducing sheath with the valved stent was then advanced over that wire and pushed gently with rotational movements to cross the infundibular wall into the RVOT (Figure 2). After correct positioning controlled by fluoroscopic guidance, the valved stent was ejected from the sheath by keeping the inner dilator fixed while the outer sheath was slowly withdrawn, allowing immediate deployment of the valved stent. Bleeding was controlled by tightening of the purse string. Assessment of the valve performance was performed by echocardiography using epicardial scanning with a transducer wrapped in a sterile sleeve. Following the procedure, the ventriculotomy was closed with the suture of the purse and chest in layers by using resorbable sutures. After extubation, animals were settled in standard conditions, with food and drink ad libitum. All animals received $1000 \mathrm{mg}$ of ceftriaxon and $500 \mathrm{mg}$ of aspirin for the first postoperative week on a daily basis. For pain control, a transdermal fentanyl patch was applied for the first 2 days after implantation.

\section{Follow-up Protocol}

Animals were evaluated by routine Doppler echocardiographic follow-up after 7 days, 1 month, and 4 months using Vingmed CFM 800 with a $5-\mathrm{MHz}$ probe. Evaluation criteria were: peak systolic gradient across the valved stent and pulmonary valve competence analyzed by color Doppler mapping and graded as mild, moderate, and severe. Euthanasia was performed under the same protocol of analgesia and anesthetic procedures as for implantation. Before death at day 7, 1
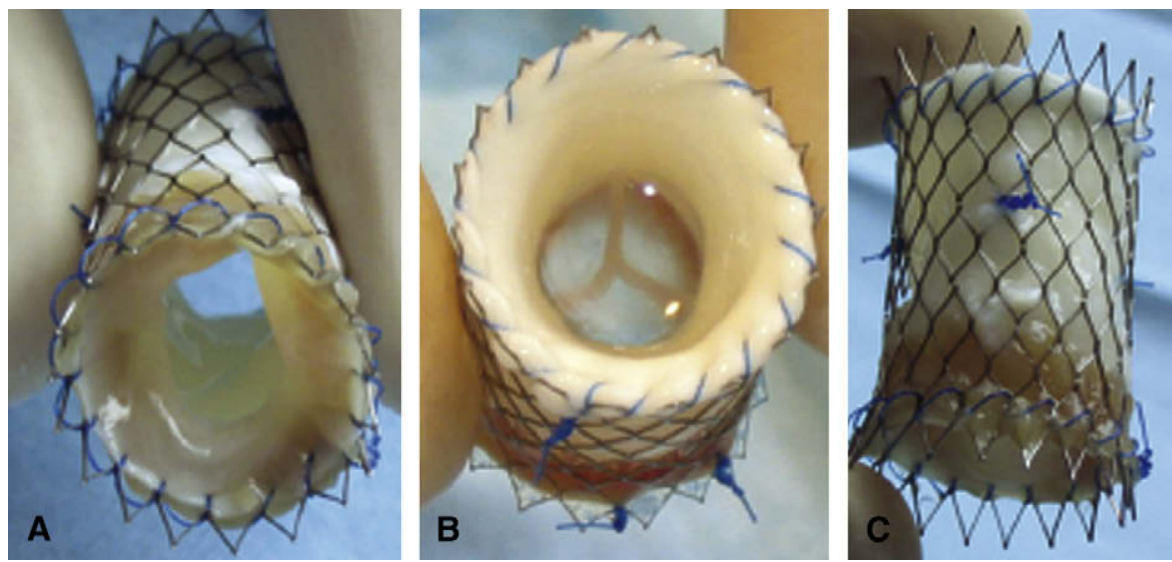

FIGURE 1. Gross appearance of the valved stent. A, Only a thin ridge of subvalvular muscle tissue remains proximally within the stent. B, The porcine xenograft valve is sewed distally and proximally by a running suture on the self-expandable stent. Notice the normal tricuspid aspect of the valve and its competence. C, Additional sutures are realized in the middle part of the valved stent on 4 cardinal points to avoid hammock aspect. 


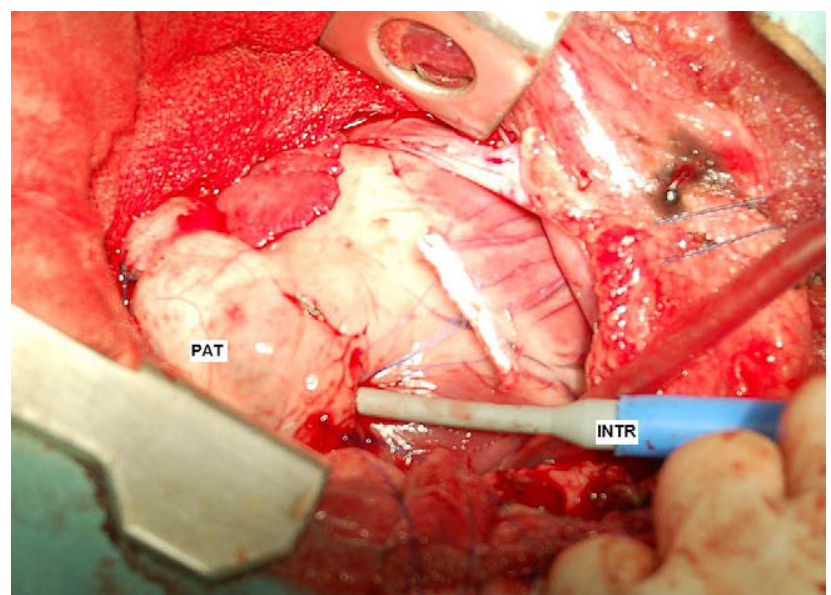

FIGURE 2. The large introducer system with the valved stent is advanced and pushed gently with rotational movements to cross the infundibular wall into the right ventricular outflow tract. It has a $2-\mathrm{cm}$ conical-shaped tip to allow smooth transition between the tip and the sheath to avoid trauma at implantation. PAT, Pulmonary artery trunk; INTR, 22/24 F introducer.

month, or 4 months after implantation, heparin was administrated and cardiac catheterization with hemodynamic calculations and angiography was performed to detect valved stent abnormalities and to measure transvalvular gradient.

\section{RESULTS}

Valve insertion was attempted in 15 lambs and succeeded in all. The overall procedure times was 100 minutes, but duration from puncture of RVOT, delivery, and valve deployment to infundibular closure was less than 10 minutes. After release, valves were deployed in RVOT in less than $5 \mathrm{sec}-$ onds. All animals survived the operative procedure. One died the day after from a pneumothorax but postmortem examination revealed a functional pulmonary valve. Another died 3 weeks after implantation from endocarditis leading to severe obstruction of the valved stent.

Functionally, Doppler echocardiography demonstrated good valvular function in the remaining animals without significant regurgitation or stenosis with time. Detailed results

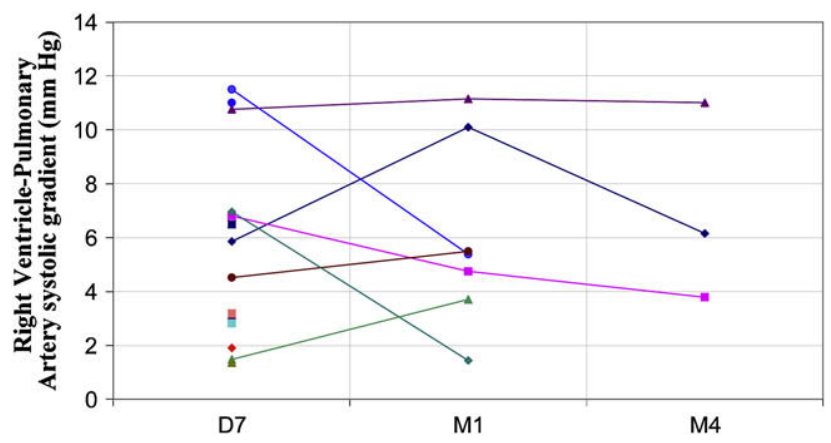

FIGURE 3. Pulmonary transvalvular systolic gradient by Doppler echocardiography at day 7 and 1 and 4 months after implantation. $D$, Day; $M$, month.

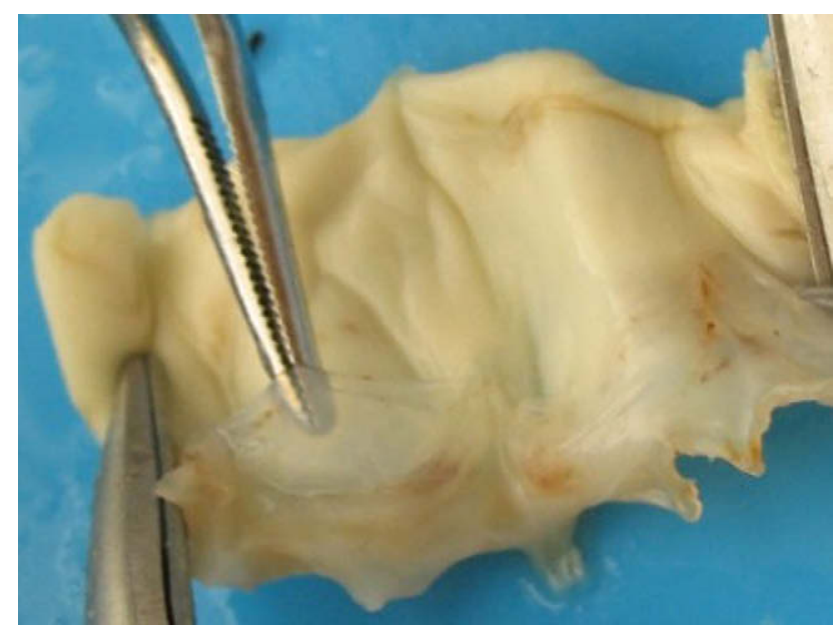

FIGURE 4. Macroscopic examination after fixation in paraformaldehyde solution showing persistent thin aspect of the pulmonary valve leaflet, 4 months after implantation.

of systolic pulmonary valve gradient are reported in Figure 3. Mild pulmonary regurgitation was noticed in 1 lamb at day 7 , in 2 lambs at month 1 , and in 1 lamb at month 4 after implantation. In addition, 4 lambs exhibited a small paraprosthetic leak at the 1 week.

Four animals were sacrificed at day 7, 4 at 1 month, and 5 at 4 months. Control cardiac catheterization performed just before sacrifice displayed a systolic pulmonary valve gradient of $18.5 \pm 12.4 \mathrm{~mm} \mathrm{Hg}$ (range $2.0-29.0 \mathrm{~mm} \mathrm{Hg}$ ) at day $7,13.5 \pm 10.6 \mathrm{~mm} \mathrm{Hg}$ (range $4.0-25.0 \mathrm{~mm} \mathrm{Hg}$ ) at 1 month, and $4.3 \pm 4.9 \mathrm{~mm} \mathrm{Hg}$ (range $1-10 \mathrm{~mm} \mathrm{Hg}$ ) at 4 months. Following sacrifice, gross anatomic examination demonstrated connective tissue between the valved stent and pulmonary wall, which increased with time: none in the 4 lambs at day 7, proximally in 1 of the 4 lambs at 1 month, and both proximally and distally in all 5 lambs sacrificed at 4 months (Figure 4). Valve morphology was normal with functional competence in all animals but 2 . In these 2 animals killed at 4 months, valves exhibited a restrictive mobility due to small leaflet retraction leading to insignificant obstruction or regurgitation (as shown by the echocardiographic study).

\section{DISCUSSION}

In congenital heart disease, pulmonary valve replacement is frequently needed. The most frequent reason is pulmonary valve incompetence following repaired tetralogy of Fallot with the transannular patch technique, which is realized in up to $70 \%$ of patients. The consequence is a pulmonary regurgitation leading to right ventricular volume overload, dilatation, and possible severe right ventricular dysfunction, leading to significant late morbidity and mortality. ${ }^{10}$ In addition, the transannular patch induces frequent dilatation and/ or aneurysm of the main pulmonary artery. In this work, we 
report an efficient hybrid approach for pulmonary valve replacement. Innovative surgical techniques are usually less invasive and tend to improve patient outcome, length of hospital stay, and perioperative mortality and morbidity.

The most often described innovative approach is the percutaneous pulmonary valve replacement as reported by Bonhoeffer, with the Melody Transcatheter Pulmonary Valve (Medtronic Inc, Minneapolis, Minn). ${ }^{3}$ However, this technique is actually limited to calcified pulmonary prosthetic conduit not exceeding 22-mm diameter and mainly restricted to adolescents and adults. ${ }^{11}$ In fact, such procedure is not the answer for patients with repaired tetralogy of Fallot by transannular patch who clearly have a dilated or even aneurysmal pulmonary artery requiring a larger-diameter device.

The transventricular approach clearly has some advantages. First, it decreases distance to the target site and provides the ability to deliver a large introducing system without cardiopulmonary bypass. ${ }^{12}$ Second, it is not limited by a possible "size mismatch" between access vessel and delivery system. Third, it allows off-pump pulmonary valve replacement. A transventricular approach was first used by Berdat and Carrel $^{5}$ in 4 children, using a Shelhigh injectable porcine pulmonic valve mounted in a self-expandable stent. This technique, very similar to that reported here, was successful for valve delivery and placement, but 1 child required reoperation 2 months later due to valve migration with severe pulmonary artery obstruction. A similar technique of implantation has been more recently reported with success in 6 patients, but once again, 1 patient with huge RVOT required homograft insertion 2 days later due to significant paravalvular leak. ${ }^{6}$ In our experience, we resolved these limitations by first reducing the diameter of the main pulmonary artery with a band to decrease the risk of valved stent migration in the pulmonary vasculature. Valve embolization could also be anticipated by securing valve position by several additional transmural sutures at the proximal and distal rim of the valved stent during implantation. ${ }^{13,14}$ In fact, the transventricular approach appears to be a real alternative for patients with repaired tetralogy of Fallot and huge pulmonary trunk. This latter, which is limiting factor for transvenous approach, could also in theory be reduced by external lateral plication just before valve replacement. In addition, as available with bovine or porcine xenograft, we anticipate that valves bigger than $22 \mathrm{~mm}$ could be inserted without increasing dramatically the size of the whole device, making possible a pulmonary valve replacement by the hybrid technique in humans with no implant size restriction. ${ }^{6}$ Finally, it could probably be performed through a ministernotomy or left anterior lateral thoracotomy. ${ }^{11,12,15}$

Many valvular substitutes have been employed for valve replacement, including homograft, pulmonary or aortic xenograft with different kinds of preparation, bovine jugular vein, pericardial valve, tissue-engineered valve, among others. ${ }^{15-17}$ Most of them have well-known limitations, including thrombogenicity, susceptibility to infection, and lack of growth potential. If human homograft valve is usually considered as the "gold standard," its availability is very restricted, especially in young patients. Actually, none of the currently used heart valves meet the criteria for an ideal valve replacement, and all have limited durability. ${ }^{15}$ These limitations have led us to investigate others strategies of valve preparation and implantation. ${ }^{7,9}$ In this study, we focused on the possibility to adapt a new hybrid approach to a biologic valve substitute with decreased immunogenicity and better biocompatibility. We used a decellularized porcine xenograft prepared in our laboratory by a nonenzymatic decellularization technique as previously described. $^{7,8}$ This valve substitute remained satisfactory at 4-month follow-up after surgical implantation. ${ }^{9}$ In the present study, we did not observe any calcification of this stented decellularized valve. Furthermore, 4 months after implantation, the wall and leaflets remained thin and smooth and no thrombosis was observed (Figure 4). The midterm hemodynamic results were satisfactory with very low transvalvular gradient, as compared with pulmonary homografts. Further studies with long-term observation are needed to appreciate the actual durability of this valve.

The main study limitation is probably the dissection of the pulmonary trunk that will probably be more complex in patients with repaired tetralogy of Fallot because of the postsurgical adherences, which were not present in this experimental work. This difficulty could possibly be overcome by lateral plication of the main pulmonary trunk combined with transmural sutures to secure valved stent positioning.

In conclusion, we report a hybrid approach using a decellularized porcine valve mounted in a self-expandable stent to replace the pulmonary valve, without cardiopulmonary bypass. This technique was found to be safe and effective, and the new valved stent was able to function up to 4 months in the pulmonary circulation. In addition, the hybrid approach allowed reduction of the main pulmonary artery before implantation, which has a major indication in patients with pulmonary incompetence following repaired tetralogy of Fallot with the transannular pulmonary patch technique. However, no data are yet available on the long-term function of this decellularized valved stent, and further long-term studies are mandatory before considering human applications.

We thank Michel Pottier and Arnold Dive for their help in animal care.

\section{References}

1. Therrien J, Provost Y, Merchant N, Williams W, Colman J, Webb G. Optimal timing for pulmonary valve replacement in adults with tetralogy of Fallot repair. Am J Cardiol. 2005;95:779-82.

2. Bonhoeffer P, Boudjemline Y, Saliba Z, Merckx J, Aggoun Y, Bonnet D, et al. Percutaneous replacement of pulmonary valve in a right-ventricle to pulmonary-artery prosthetic conduit with valve dysfunction. Lancet. 2000;356:1403-5. 
3. Bonhoeffer P, Boudjemline Y, Qureshi S, Le Bidois J, Iserin L, Acar P, et al. Percutaneous insertion of the pulmonary valve. J Am Coll Cardiol. 2002;39: 1664-9.

4. Khambadkone S, Coats L, Taylor A, Boudjemline Y, Derrick G, Tsang V, et al. Percutaneous pulmonary valve implantation in humans. Results in 59 consecutive patients. Circulation. 2005;112:1189-97.

5. Berdat PA, Carrel P. Off-pump pulmonary valve replacement with the new Shelhigh injectable stented pulmonic valve. J Thorac Cardiovasc Surg. 2006;131: 1192-4.

6. Schreiber C, Hörer J, Vogt M, Fratz S, Kunze M, Galm C, et al. A new treatment option for pulmonary valvar insufficiency: first experiences with implantation of a self-expanding stented valve without the use of cardiopulmonary bypass. Eur J Cardiothorac Surg. 2007;31:26-30.

7. Juthier F, Vincentelli A, Gaudric J, Corseaux D, Fouquet O, Calet C, et al. Decellularized heart valve as a scaffold for in vivo recellularization: deleterious effects of granulocyte colony-stimulating factor. J Thorac Cardiovasc Surg. 2006;131: 843-52.

8. Booth C, Korossis SA, Wilcox HE, Watterson KG, Kearney JN, Fisher J, et al. Tissue engineering of cardiac valve prostheses I: development and histological characterization of an acellular porcine scaffold. J Heart Valve Dis. 2002;11: 457-62.

9. Vincentelli A, Wautot F, Juthier F, Fouquet O, Corseaux D, Marechaux S, et al. In vivo autologous recellularization of tissue-engineered heart valve: are bone marrow mesenchymal stem cells the best candidates? J Thorac Cardiovasc Surg. 2007; 134:424-32.
10. Gatzoulis MA, Balaji S, Webber SA, Siu SC, Hokanson JS, Poile C, et al. Risk factors for arrhythmia and sudden cardiac death late after repair of tetralogy of Fallot a multicentre study. Lancet. 2000;356:975-81.

11. Zhou JQ, Corno AF, Huber CH, Tozzi P, von Segesser LK. Self-expandable valved stent of large size: off-bypass implantation in pulmonary position. Eur J Cardiothorac Surg. 2003;24:212-6.

12. Huber CH, von Segesser LK. Direct access valve replacement (DAVR)—are we entering a new era in cardiac surgery? Eur J Cardiothorac Surg. 2006;29:380-5.

13. Boudjemline Y, Schievano S, Bonnet C, Coats L, Agnoletti G, Khambadkone S, et al. Off-pump replacement of the pulmonary valve in large right ventricular outflow tracts: a hybrid approach. J Thorac Cardiovasc Surg. 2005; 129:831-7.

14. Dittrich S, Gloeckler M, Arnold R, Sarai K, Siepe M, Beyersdorf F, et al. Hybrid pulmonary valve implantation: injection of self-expanding tissue valve through the main pulmonary artery. Ann Thorac Surg. 2008;85:632-4.

15. Stock UA, Nagashima M, Khalil PN, Nollert GD, Herden T, Sperling JS, et al Tissue-engineered valved conduits in the pulmonary circulation. J Thorac Cardiovasc Surg. 2000;119:732-40.

16. Steinhoff G, Stock U, Karim N, Mertsching H, Timke A, Meliss RR, et al. Tissue engineering of pulmonary heart valves on allogenic acellular matrix conduits. In vivo restoration of valve tissue. Circulation. 2000;102(suppl 3):III50-5.

17. Dohmen PM, Lembcke A, Holinski S, Kivelitz D, Braun JP, Pruss A, et al. Midterm clinical results using a tissue-engineered pulmonary valve to reconstruct the right ventricular outflow tract during the Ross procedure. Ann Thorac Surg. 2007; 84:729-36. 